\title{
Intestinal Transportations of Main Chemical Compositions of Polygoni Multiflori Radix in Caco-2 Cell Model
}

\author{
Jie Yu, Na Li, Pei Lin, Yunfei Li, Xiaojian Mao, Getuzhaori Bao, \\ Wen Gu, and Ronghua Zhao
}

\author{
Yunnan University of Traditional Chinese Medicine, Kunming, Yunnan 650500, China \\ Correspondence should be addressed to Ronghua Zhao; kmzhaoronghua@hotmail.com
}

Received 30 October 2013; Accepted 19 December 2013; Published 12 February 2014

Academic Editor: Waris Qidwai

Copyright (c) 2014 Jie Yu et al. This is an open access article distributed under the Creative Commons Attribution License, which permits unrestricted use, distribution, and reproduction in any medium, provided the original work is properly cited.

\begin{abstract}
Context. Polygoni Multiflori Radix (PMR) is originated from the root of Polygonum multiflorum Thunb. and used in oriental countries for centuries. However, little researches pay close attention to the absorption of its major constituents. Objective. Transepithelial transport of TSG, RL, PL, and four anthraquinones is carried out. Materials and Methods. Caco-2 cell monolayer, which represented a well-established model for the study of intestinal transport of nutrients and xenobiotics, was used in this paper. Results. The apparent permeability coefficients $\left(P_{\text {app }}\right)$ in the Caco- 2 cell monolayers were TSG $\left(2.372 \times 10^{-9}\right)<\mathrm{EG}\left(2.391 \times 10^{-9}\right)$ $<\operatorname{EN}\left(2.483 \times 10^{-9}\right)<\mathrm{PL}\left(4.917 \times 10^{-9}\right)<\mathrm{RN}\left(1.707 \times 10^{-8}\right)<\mathrm{RL}\left(1.778 \times 10^{-8}\right)<\mathrm{AE}\left(1.952 \times 10^{-8}\right)$. Thus, RN, RL, and AE were considered partly absorbed, while other constituents were hardly absorbed. Discussion and Conclusion. Glycosides showed poor permeabilities than aglycones. In the meantime, TSG and EN gave out poor recovery rates in this assay, which indicated that TSG and EN may accumulate or metabolise in the Caco-2 cells. In silico prediction indicated that Gibbs energy $(r=0.751, p<0.05)$ and heat of form $(r=0.701, p<0.05)$ were strongly positively correlated with $P_{\text {app. }}$.
\end{abstract}

\section{Introduction}

Polygoni Multiflori Radix ((PMR), heshouwu in Chinese) and Polygoni Multiflori Radix Praeparata ((PMRP), zhiheshouwu in Chinese) are originated from the root of Polygonum multiflorum Thunb. (Polygonaceae) and used in the treatment of nonalcoholic fatty liver disease (NAFLD) and hyperlipidemia in oriental countries for centuries (Figure 1).

Preliminary researches [1-4] indicate that Polygoni Multiflori Radix mainly contains stilbene glycosides $\left(2,3,5,4^{\prime}\right.$ tetrahydroxystilbene-2-O- $\beta$-D-glucoside (TSG), resveratrol $(\mathrm{RL})$, polydatin (PL), and others) and anthraquinones (emodin (EN), rhein (RN), aloe-emodin (AE), emodin-8$O-\beta$-D-glucopyranoside (EG), and others). In our previous research, TSG displayed the most important role in the total cholesterol (TC) lowering effect among all the chemical constituents of Polygonum multiflorum. The quality of PMR was evaluated by the contents of TSG and anthraquinones as regulated by the Pharmacopoeia of the People's Republic of China, 2010 edition [5].
However, little researches pay close attention to the absorption of these major constituents of PMR. In this research, transepithelial transport of TSG, RL, PL, and the four anthraquinones is carried out using human Caco-2 cell monolayer as a model system. Caco- 2 cells, derived from a human colon adenocarcinoma, spontaneously differentiate after reaching confluence in culture, exhibiting several morphological and functional characteristics of mature enterocytes. Caco-2 cell monolayers represent a well-established model for the study of intestinal transport of nutrients and xenobiotics and are widely used in pharmacology and toxicology researches [6-10]. This research provided important predictive information regarding the oral bioavailability of TSG, RL, PL, EN, RN, AE, and EG.

\section{Materials and Methods}

2.1. Caco-2 Cell. Caco-2 cell (the human colon adenocarcinoma cell) was purchased from Kunming Institute of Zoology, Chinese Academy of Sciences, in June 2009. 


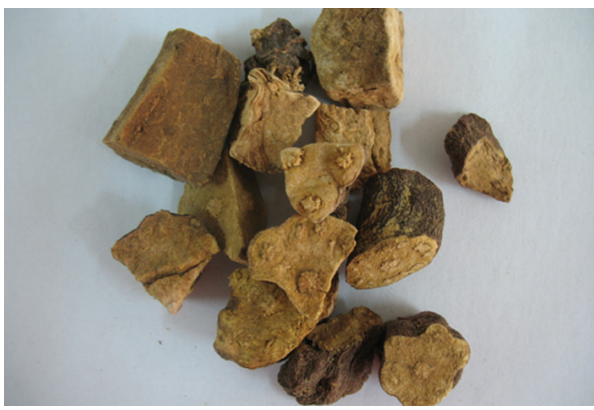

PMR

(a)

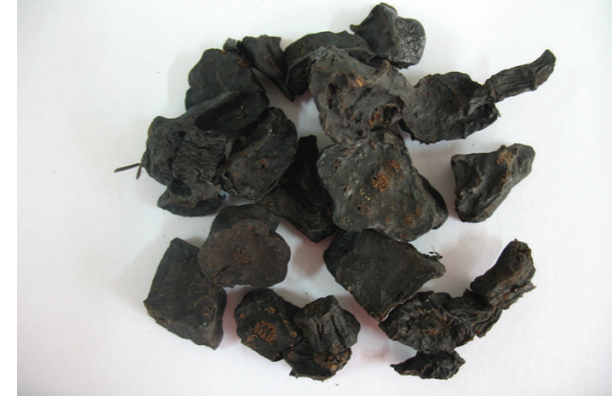

PMRP

(b)

FIgure 1: Photographs of Polygoni Multiflori Radix and its processed products. (a) PMR: Polygonum Multiflorum Radix. (b) PMRP: Polygoni Multiflori Radix Praeparata.

2.2. Chemicals. TSG, EN, RN, AE, RL, and PL were purchased from National Institute for the Control of Pharmaceutical and Biological Products, China. EG was purchased from the Sichuan Xianxin Biotech Co., Ltd., China. The purities of all the standards were not less than 98\%. Propranolol (PR) was used as positive control substance of high permeability. Atenolol (AT) was used as positive control substance of poor permeability. Both PR and AT were purchased from Sigma. Structures of them were listed in Figure 2.

Dulbecco's Modified Eagle's Medium (DMEM) and fetal bovine serum (FBS) were obtained from Gibco Invitrogen Corporation. Phosphate buffer solution (PBS), N-2hydroxyethylpiperazine- $\mathrm{N}^{\prime}$-2-ethanesulfonic acid (HEPES), L-glutamine, and pyruvic acid sodium salt were of chemical or analytical grade obtained from domestic company. Dimethyl sulfoxide (DMSO) was purchased from Sigma Chemical Co. (Deisenhofen, Germany).

2.3. Culture Conditions. Caco-2 cells were cultured in DMEM containing $1 \mathrm{~g} / \mathrm{L}$ D-glucose, $2 \mathrm{~g} / \mathrm{L} \mathrm{NaHCO}_{3}, 165 \mathrm{mg} / \mathrm{L}$ pyruvic acid sodium salt, and $150 \mathrm{mg} / \mathrm{L}$ L-Glutamine, supplemented with $10 \%$ FBS. Cultures were maintained in a humidified incubator with 5\% carbon dioxide 95\% air at $37^{\circ} \mathrm{C}$. $0.25 \%$ of trypsin (Sigma, USA) $(0.25 \%)$ was used to passage cells at $80-90 \%$ confluence and seeded at a density of about $1 \times 10^{5}$ cells/mL on a 12 -well Transwell (Corning Costar, Cambridge, MA, USA) insert filter (surface area = $1.13 \mathrm{~cm}^{2}$, pore size $=3 \mu \mathrm{m}$ ). The cells were left to grow for 21 days to reach confluence and differentiation, so that Caco2 cells were fully differentiated in this assay and used for further experiments. All cells used in this study were between passages 20 and 35 .

2.4. Standardized Conditions. The Caco-2 cell system was validated by the transepithelial electrical resistance (TEER) assay (by EVOM2 from the World Precision Instrument Trading Co., Ltd.) and the alkaline phosphatase (ALP) activity difference between the two sides of the membrane. The TEER values $>500 \Omega / \mathrm{cm}$ were required. The activities of ALP, as a specific brush border formation enzyme marker, in both AP and $\mathrm{BL}$ sides were estimated. The $\mathrm{ALP}_{\mathrm{AP}} / \mathrm{ALP}_{\mathrm{BL}}$ ratio was calculated.

2.5. Permeability Studies. The stock solutions of all tested compounds were achieved by dissolving them in dimethylsulfoxide (DMSO) at a concentration of $5 \mathrm{mmol} / \mathrm{mL}$. Then they were further diluted with PBS to graded concentrations of $100 \mu \mathrm{M}$ and $200 \mu \mathrm{M}$.

The following experiment was undertaken to measure the flux of the standards. Flux describes the movement of a substance across polarized Caco-2 monolayers either in absorptive (apical $\rightarrow$ basolateral, $\mathrm{AP} \rightarrow \mathrm{BL}$ ) or secretary direction (basolateral $\rightarrow$ apical, BL $\rightarrow$ AP). Absorption assay was carried out in this research. The monolayers were washed twice with warm transport medium PBS within $30 \mathrm{~min}$ and then sequentially incubated once for $30 \mathrm{~min}$ at $37^{\circ} \mathrm{C}$ with PBS. Transport medium $(0.5 \mathrm{~mL})$ containing TSG, EN, RN, AE, $\mathrm{RL}$, PL or EG was added to the AP side, while the receiving chamber contained the corresponding volume $(1.5 \mathrm{~mL})$ of transport medium. After shaking at $55 \mathrm{r} / \mathrm{min}$ for $1.5 \mathrm{~h}$ at $37^{\circ} \mathrm{C}$ in a shaking water bath, samples were collected $(0.4 \mathrm{~mL}$ and $1.2 \mathrm{~mL}$ in 1 der constituents the AP and BL sides, resp.) from both sides of the Caco- 2 cell monolayers and immediately frozen, lyophilized, and preserved below $-20^{\circ} \mathrm{C}$ [11].

2.6. HPLC-DAD Analysis of Samples. To determine the concentration of corresponding constituents in both AP and $\mathrm{BL}$ sides, the lyophilized samples of $\mathrm{AP}$ and $\mathrm{BL}$ sides were dissolved in quantitative methanol by ultrasound for $20 \mathrm{~min}$ and then filtered by $0.45 \mu \mathrm{m}$ filtration membranes.

All experiments were performed with Dionex Ultimate 3000 HPLC system (Dionex Technologies, USA), which included a binary pump, an autosampler, a column oven, and a diode array detector plus on-line degasser. Data were analyzed with Chromeleon 6.8.

The separation of samples was achieved on Zorbax SB$\mathrm{C}_{18}$ analytical column $(4.6 \times 250 \mathrm{~mm}, 5 \mu \mathrm{m}$ particle diameter, supplied by Agilent Technologies, USA). 
<smiles>[R]c1cc(O)c2c(c1)C(=O)c1cc(Br)cc(O)c1C2=O</smiles>

$$
\begin{array}{lll}
\mathrm{EN} & \mathrm{R}_{1}=\mathrm{OH} & \mathrm{R}_{2}=\mathrm{CH}_{3} \\
\mathrm{AE} & \mathrm{R}_{1}=\mathrm{H} & \mathrm{R}_{2}=\mathrm{CH}_{2} \mathrm{OH} \\
\mathrm{RN} & \mathrm{R}_{1}=\mathrm{H} & \mathrm{R}_{2}=\mathrm{COOH}
\end{array}
$$

(a) Anthraquinones<smiles>OCC1C(O)C(Oc2c(O)cc(O)cc2/C=C/c2ccc(O)cc2)OCC(O)[C@H](O)C1O</smiles>

(c) TSG<smiles>OCC1OC(Oc2cc(O)cc(/C=C/c3ccc(O)cc3)c2)C(O)C(O)C1O</smiles>

(e) PL<smiles>Cc1cc(O)c2c(c1)C(=O)c1cc(O)cc(OC3OC(CO)C(O)C(O)C3O)c1C2=O</smiles>

(b) EG<smiles>Oc1ccc(/C=C/c2cc(O)cc(O)c2)cc1</smiles>

(d) $\mathrm{RL}$<smiles>CC(C)NCC(O)COc1ccc(CC(N)=O)cc1</smiles>

(f) PR<smiles>CCNCC(O)COc1cccc2ccccc12</smiles>

FIGURE 2: Structures of analytes in this research.

Isocratic and gradient elution with mobile phase consisting of (A) $0.1 \% \mathrm{H}_{3} \mathrm{PO}_{4}$ and (B) methanol was used. Methanol percentage and detection wavelength were listed in Table 1. The oven temperature was set at $30^{\circ} \mathrm{C}$ and the flow rate was set at $1.0 \mathrm{~mL} / \mathrm{min}$.

2.7. Standard Curve. The calibration curves for TSG, EN, RN, $\mathrm{AE}, \mathrm{RL}$, and PL were constructed by plotting concentration $(Y, \mu \mathrm{mol})$ versus peak area $(X)$. The linear equation, linear range, and correlation coefficient were listed in Table 2.

\subsection{Calculation of the Apparent Permeability Coefficient $\left(P_{a p p}\right)$} and Recovery Rate. The apparent permeability coefficient $\left(P_{\text {app }}\right)$ was calculated as follows:

$$
P_{\text {app }}(\mathrm{cm} / \mathrm{s})=\frac{d Q}{d t} \times \frac{1}{60} \times \frac{1}{A} \times \frac{1}{C_{0}},
$$

where $P_{\text {app }}$ was the apparent permeability coefficient in $\mathrm{cm} / \mathrm{s}$; $d Q / d t$ was the rate of appearance of the test compound on the receiver side in $\mu \mathrm{mol} / \mathrm{min} ; C_{0}$ was the initial concentration of test compound on the donor side in $\mu \mathrm{moL} / \mathrm{L}$; and A was the surface area of the Transwell in $\mathrm{cm}^{2}$.

Meanwhile, the recovery rate of each compound was calculated as follows:

Recovery (\%)

Total compound in donor and receiver at the end of the experiment $(\mu \mathrm{M})$ Initial compound present $(\mu \mathrm{M})$

$\times 100 \%$.

2.9. Quantitative Relationships between Physical-Chemical Parameter, Transepithelial Flux, and Recovery Rate. In silico 
TABLE 1: Elution procedure and detection wavelength of high performance liquid chromatography assays.

(a) Isocratic elution procedure, detection wavelength, and $R_{t}$ of $\mathrm{EN}, \mathrm{AE}, \mathrm{RL}$, PL, and EG

\begin{tabular}{lccc}
\hline Sample & Detection wavelength $(\mathrm{nm})$ & $\mathrm{B} \%$ & $R_{t}(\mathrm{~min})$ \\
\hline $\mathrm{EN}$ & 287 & 75 & 11.24 \\
$\mathrm{AE}$ & 254 & 80 & 5.042 \\
$\mathrm{RL}$ & 306 & 45 & 8.423 \\
$\mathrm{PL}$ & 306 & 40 & 6.568 \\
$\mathrm{EG}$ & 280 & 55 & 12.11 \\
\hline
\end{tabular}

(b) Gradient elution procedure, detection wavelength, and $R_{t}$ of TSG and $\mathrm{RN}$

\begin{tabular}{lccccc}
\hline Sample & $\begin{array}{c}\text { Detection } \\
\text { wavelength }(\mathrm{nm})\end{array}$ & $0 \mathrm{~min}$ & $5 \mathrm{~min}$ & $10 \mathrm{~min}$ & $R_{t}(\mathrm{~min})$ \\
\hline TSG & 320 & 40 & 55 & 70 & 6.513 \\
RN & 254 & 85 & $/$ & 90 & 5.307 \\
\hline
\end{tabular}

Mobile phase A: $0.1 \% \mathrm{H}_{3} \mathrm{PO}_{4}$.

Mobile phase B: methanol.

prediction of physical, thermodynamic, and chemical parameters properties of analytes was made in this research. Basic physical and thermodynamic properties of these analytes, such as molecular weight, boiling point, Gibbs energy, and Henry's Law, were all predicted by ChemDraw Pro. Then we calculated the $\log P$ (by ChemDraw Ultra 8.0), $\operatorname{Clog} P$ (by ChemDraw Ultra 8.0, The OSIRIS Property Explorer, and The Bio-Lim., resp.), and solubility (by The OSIRIS Property Explorer) of these constituents.

Relationships between these physical, thermodynamic, and chemical parameters and $P_{\text {app }}$ and recovery rate were assessed with Pearson's correlation coefficient. Results were classified into two significance levels using the $p$ values of 0.05 and 0.01 .

\section{Results}

3.1. The Integrity and Polarity of Caco-2 Cell Monolayer Membrane. The integrity of Caco- 2 cell monolayer was evaluated by TEER value between AP side and BL side on alternate days through the 21-day culture period (Figure 3 ). The TEER value was rising continuously from the beginning to the 18th day of this research. The TEER value tended to be stable from the 18th day $(551.7 \pm 76.87)$ to the 20 th day $(578.4 \pm 80.40)$, which indicated that a tight Caco-2 monolayer had been formed.

The $\mathrm{ALP}_{\mathrm{AP}} / \mathrm{ALP}_{\mathrm{BL}}$ ratio was increasing from the 2nd day to the 14th day and maintained in the maximum level from the 14th day to the 21st day (Figure 4). The activity of alkaline phosphatase in the AP side was almost ten times than that in BL side, which could further confirm the Caco- 2 cells differentiation.

3.2. The $P_{a p p}$ Values and Recovery Rate of TSG, EN, RN, AE, $R L, P L$, and EG through the Caco-2 Monolayer. The concentrations of analytes in AP and BL sides were analyzed after 90 mins incubation by HPLC-DAD equipment. The recovery

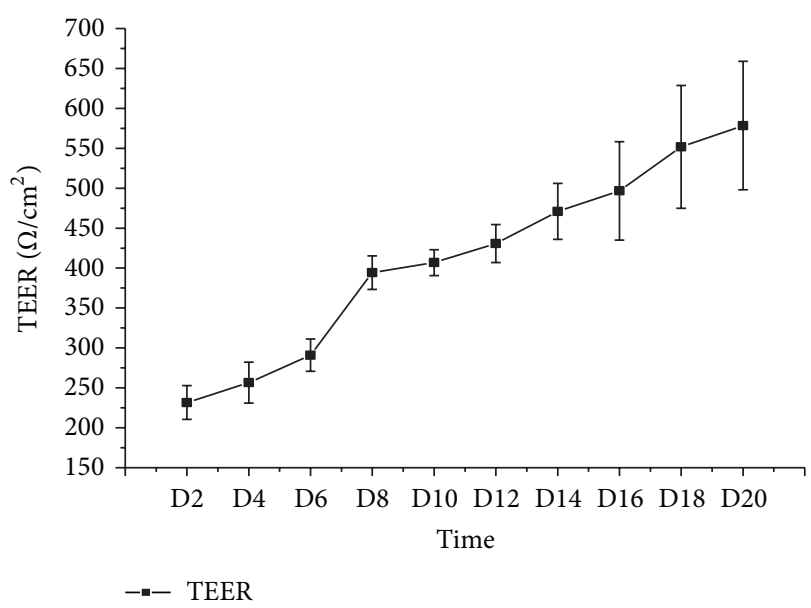

FIGURE 3: The value of transepithelial electrical resistance (TEER) (Mean $\pm \mathrm{SD}, n \geq 6, \Omega / \mathrm{cm}^{2}$ ).

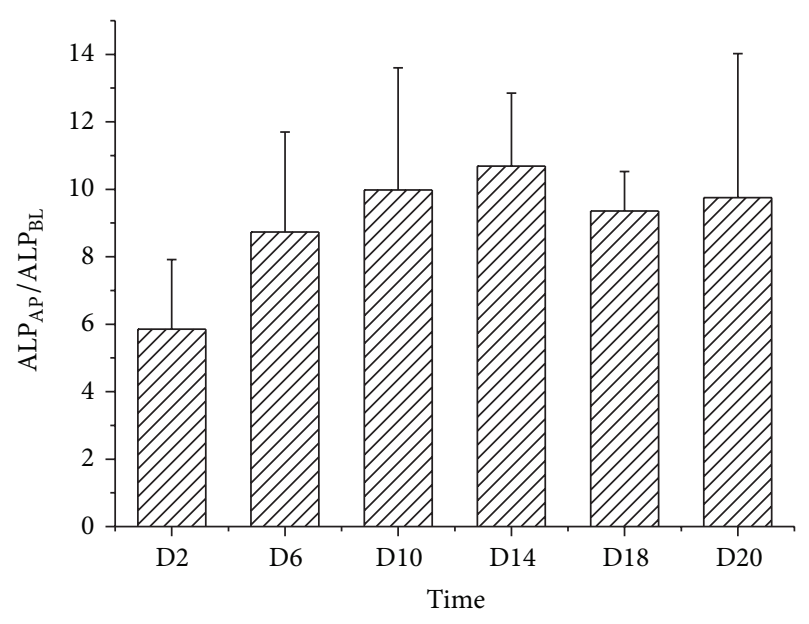

FIgURE 4: The alkaline phosphatase ratio (apical side to basolateral side, $\left.\mathrm{ALP}_{\mathrm{AP}} / \mathrm{ALP}_{\mathrm{BL}}\right)$ in this assay (Mean $\pm \mathrm{SD}, n \geq 6$ ).

rates and $P_{\text {app }}$ values of seven compounds were listed in Table 3 and Figure 5.

$\mathrm{RN}, \mathrm{PR}$, and AT showed favorable recovery rates around $100 \%$. AE, RL, PL, and EG exhibited middle extent (30 80\%) recovery. EN and TSG gave out very poor recovery rate of only $14.48 \pm 2.504 \%$ and $17.39 \pm 1.600 \%$. Usually, the poor recovery may indicate problems with poor solubility, binding of the compound to the plate, metabolism by the Caco- 2 cells, or accumulation of the compound in the cell monolayer. We predict that large partitions of EN and TSG may accumulate or metabolise in the Caco- 2 cells. However, further validation must be carried out to confirm this hypothesis.

Small $P_{\text {app }}$ of TSG, EG, and PL (smaller than that of AT) reflected that they were hardly absorbed by human intestinal epithelial cells. This conformed with our consensus that glycosides were poorly absorbed than their aglycone due to the low fat solubility and low hydrophobicity. EN also showed small $P_{\text {app }}$ probably due to its low recovery rate mentioned above. RN, RL, and AE showed middle $P_{\text {app }}$ between atenolol 
TABLE 2: The linear equation, linear range, and correlation coefficient of nine analytes $(n=6)$.

\begin{tabular}{lccr}
\hline Sample & Linear equation & Related coefficient & Linear range $(\mu \mathrm{mol})$ \\
\hline TSG & $Y=29836 X+0.1657$ & 0.9987 & $4.305 \times 10^{-6}-3.444 \times 10^{-4}$ \\
EN & $Y=18775 X+0.0051$ & 1 & $2.664 \times 10^{-5}-1.066 \times 10^{-3}$ \\
RN & $Y=22458 X+0.2069$ & 0.9992 & $2.322 \times 10^{-5}-9.288 \times 10^{-4}$ \\
AE & $Y=23601 X-0.1580$ & 0.9996 & $2.664 \times 10^{-5}-1.066 \times 10^{-3}$ \\
RL & $Y=50841 X+0.2434$ & 0.9993 & $1.733 \times 10^{-5}-3.466 \times 10^{-4}$ \\
PL & $Y=27231 X+0.1174$ & 0.9999 & $6.892 \times 10^{-6}-6.892 \times 10^{-4}$ \\
EG & $Y=25907 X-0.0244$ & 0.9999 & $7.040 \times 10^{-6}-2.534 \times 10^{-3}$ \\
\hline
\end{tabular}

TABLE 3: The apparent permeability coefficient $\left(P_{\text {app }}\right)$ values (Mean, $n \geq 3, \mathrm{~cm} / \mathrm{s}$ ) and recovery rates (Mean $\pm \mathrm{SD}, n \geq 3$ ) of the seven analytes.

\begin{tabular}{|c|c|c|c|c|c|c|c|c|c|}
\hline Compound & TSG & EN & $\mathrm{RN}$ & $\mathrm{AE}$ & $\mathrm{RL}$ & $\mathrm{PL}$ & EG & PR & AT \\
\hline $\begin{array}{l}P_{\text {app }} \text { value } \\
(\mathrm{cm} / \mathrm{s})\end{array}$ & $2.372 \times 10^{-9}$ & $2.483 \times 10^{-9}$ & $1.707 \times 10^{-8}$ & $1.952 \times 10^{-8}$ & $1.778 \times 10^{-8}$ & $4.917 \times 10^{-9}$ & $2.391 \times 10^{-9}$ & $6.075 \times 10^{-8}$ & $1.668 \times 10^{-8}$ \\
\hline $\begin{array}{l}\text { Recovery } \\
\text { rate }(\%)\end{array}$ & $17.39 \pm 1.600$ & $14.48 \pm 2.504$ & $96.96 \pm 7.377$ & $42.36 \pm 6.323$ & $62.39 \pm 6.210$ & $59.94 \pm 9.90$ & $33.95 \pm 7.06$ & $117.1 \pm 8.85$ & $125.2 \pm 33.60$ \\
\hline
\end{tabular}

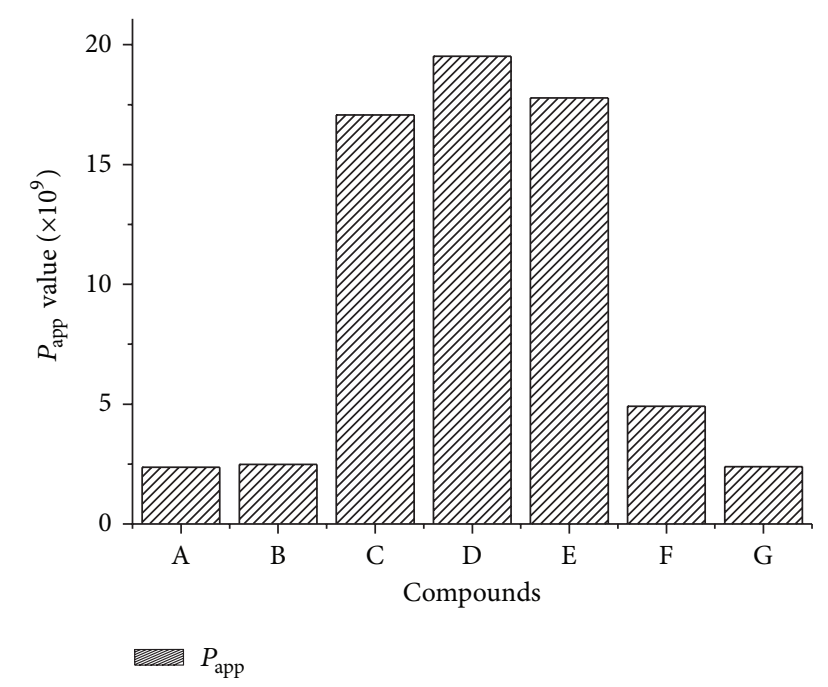

FIGURE 5: The apparent permeability coefficient $\left(P_{\text {app }}, \mathrm{cm} / \mathrm{s}\right)$ values of TSG, EN, RN, AE, RL, PL, and EG through the Caco-2 monolayer. A: $2,3,5,4^{\prime}$-tetrahydroxystilbene-2-O- $\beta$-D-glucoside (TSG), B: emodin (EN), C: rhein (RN), D: aloe-emodin (AE), E: resveratrol (RL), F: polydatin (PL), and G: emodin-8-O- $\beta$-D-glucopyranoside (EG).

(known human absorption of 50\%) and propranolol (known human absorption of 90\%) [12, 13]. Thus, RN, RL, and AE were considered partly absorbed. On the other hand, all the compounds were catalyzed to be passive-transported because the concentrations of each compound in the AP side were all higher than in the BL side.

3.3. Relationships between Physical-Chemical Properties Values and $P_{a p p}$ and Recovery. Basic physical and thermodynamic properties of these analytes, such as molecular weight, boiling point, Gibbs energy, Henry's Law, $\log P, C \log P$, and $\log S$, were listed in Table 4 .
Boiling point and melting point predicted the normal boiling and melting point for the structure, respectively. Critical temperature predicted the temperature (reported in K) above which the gas form of the structure cannot be liquefied, no matter the applied pressure. Critical pressure predicted the minimum pressure (reported as bars) that must be applied to liquefy the structure at the critical temperature. Critical volume predicted the volume occupied (reported in $\mathrm{cm}^{3} / \mathrm{mol}$ ) at the compound's critical temperature and pressure. Heat of formation was the prediction of the heat of formation for the structure (reported in $\mathrm{kJ} / \mathrm{mol}$ at 1 atm and $298.15 \mathrm{~K}$ ). Gibbs energy was the prediction of the Gibbs free energy for the structure (reported in $\mathrm{kJ} / \mathrm{mol}$ at $1 \mathrm{~atm}$ and $298.15 \mathrm{~K})$.

The $\log P$ value of a compound, which is the logarithm of its partition coefficient between $n$-octanol and water (coctanol/water), was a well-established measure of the compound's hydrophilicity. Low hydrophilicities and therefore high $\log P$ values cause poor absorption or permeation. It has been shown for compounds to have a reasonable probability of being well absorbed their $\log P$ value must not be greater than 5.0 [14].

The aqueous solubility of a compound significantly affects its absorption and distribution characteristics. Typically, a low solubility goes along with a bad absorption and therefore the general aim is to avoid poorly soluble compounds. The Solubility Prediction $(\log S)$ was calculated by The OSIRIS Property Explorer in our research, in a unit stripped logarithm (base 10) of the solubility measured in mol/liter (shown in Table 3).

Pearson's correlation coefficients between these physical, thermodynamic, and chemical parameters and $P_{\text {app }}$ and recovery were displayed in Table 5. Gibbs energy $(r=0.751$, $p<0.05)$ and heat of form $(r=0.701, p<0.05)$ were strongly positively correlated with $P_{\text {app }}$. This was the first report to show that the permeability was strongly affected by the Gibbs energy and heat of form of a compound. 
TABLE 4: The apparent permeability coefficient $\left(P_{\text {app }}\right)$ values (Mean, $n \geq 3, \mathrm{~cm} / \mathrm{s}$ ) and recovery rates (Mean $\pm \mathrm{SD}, n \geq 3$ ) of the seven analytes.

\begin{tabular}{|c|c|c|c|c|c|c|c|c|c|}
\hline Compound & TSG & EN & $\mathrm{RN}$ & $\mathrm{AE}$ & $\mathrm{RL}$ & PL & EG & $\mathrm{PR}$ & AT \\
\hline Molecular weight & 406.38 & 270.24 & 284.22 & 270.24 & 228.24 & 390.38 & 432.38 & 245.32 & 266.34 \\
\hline Boiling point (K) & 925.79 & 752.86 & 788.86 & 761.48 & 675.11 & 890.96 & 968.71 & 655.04 & 711.80 \\
\hline Melting point (K) & 992.60 & 846.01 & 894.89 & 795.11 & 629.96 & 880.88 & 1096.93 & 450.66 & 524.88 \\
\hline Critical temperature $(\mathrm{K})$ & 1166.96 & 965.47 & 996.03 & 956.41 & 898.50 & 1111.40 & 1238.72 & 833.04 & 887.27 \\
\hline Critical pressure (Bar) & 40.21 & 52.06 & 47.83 & 48.02 & 50.95 & 33.57 & 34.16 & 24.98 & 24.46 \\
\hline $\begin{array}{l}\text { Critical volume } \\
\left(\mathrm{cm}^{3} / \mathrm{mol}\right)\end{array}$ & 1011.50 & 687.50 & 695.50 & 690.50 & 631.50 & 995.50 & 1051.5 & 755.50 & 806.50 \\
\hline Gibbs energy $(\mathrm{kJ} / \mathrm{mol})$ & -795.72 & -357.13 & -546.42 & -339.33 & -91.82 & -641.10 & -906.41 & 129.98 & -50.00 \\
\hline $\begin{array}{l}\text { Molar refraction index } \\
\left(\mathrm{cm}^{3} / \mathrm{mol}\right)\end{array}$ & 100.72 & 71.27 & 71.30 & 71.36 & 66.60 & 99.03 & 103.71 & 72.41 & 73.50 \\
\hline Henry's law constant & 26.02 & 18.79 & 19.55 & 19.25 & 14.25 & 22.04 & 26.58 & 10.61 & 16.25 \\
\hline Heat of form $(\mathrm{kJ} / \mathrm{mol})$ & -1309.43 & -622.31 & -795.27 & -597.23 & -273.94 & -1132.12 & -1480.49 & -173.06 & -427.56 \\
\hline $\log P$ (by ChemDraw) & 0.83 & 1.74 & 1.2 & 1.07 & 3.06 & 1.22 & -0.1 & 2.33 & 0.50 \\
\hline Clog $P$ (by ChemDraw) & 0.6538 & 3.617 & 3.529 & 2.700 & 2.833 & 1.517 & 1.650 & 2.444 & -0.1086 \\
\hline Clog $P$ (by OSIRIS) & 0.71 & 2.93 & 2.44 & 2.29 & 3.12 & 1.64 & 0.82 & 2.41 & 0.41 \\
\hline $\log S$ (by OSIRIS) & -2.45 & -4.19 & -4.15 & -4.02 & -2.86 & -3.21 & -4.07 & -3.2 & -2.02 \\
\hline
\end{tabular}

TABLE 5: Relationships between physical-chemical properties values and apparent permeability coefficient $\left(P_{\text {app }}\right)$.

\begin{tabular}{lcc}
\hline $\begin{array}{l}\text { Correlation coefficient } \\
\text { and significance }\end{array}$ & $\begin{array}{c}\text { Pearson's correlation } \\
\text { coefficient }\end{array}$ & $\begin{array}{c}\text { Significance } \\
(p)\end{array}$ \\
\hline Molecular weight & - & - \\
Boiling point & -0.687 & 0.041 \\
Melting point & -0.768 & 0.016 \\
Critical temperature & -0.703 & 0.035 \\
Critical pressure & - & - \\
Critical volume & - & - \\
Gibbs energy & 0.751 & 0.020 \\
Molar refraction index & - & - \\
Heat of form & 0.701 & 0.035 \\
Log $P$ (by ChemDraw) & - & - \\
Clog $P$ (by ChemDraw) & - & - \\
Clog $P$ (by OSIRIS) & - & - \\
Log $S$ (by OSIRIS) & - & - \\
\hline
\end{tabular}

-: data were not listed when significance $(p)$ was higher than 0.05 .

Compounds with higher Gibbs energy and heat of form were considered to remain in higher energy state; therefore, these compounds had stronger tendency to complete the transmembrane movement. Moreover, boiling point, melting point, and critical temperature were all strongly positively correlated with $P_{\text {app }}(p<0.05)$.

\section{Discussion and Conclusion}

Previous studies $[15,16]$ reported that TSG has lipid regulation effect. Our previous researches $[17,18]$ also validated that the TSG possessed great TG reduction activity. Therefore, we could affirm that TSG is the main lipid regulation ingredient of PMR. However, in our previous studies, TSG content was significantly reduced after processed with black bean decoction (PMRP) according to the method recorded in the Pharmacopoeia of the People's Republic of China (2010 edition) [5].

In this research, TSG was estimated to be a poorly absorbed compound. The lower concentration of TSG in the processed PMRP together with its bad absorption all suggested that the dosage of PMRP should be increased in the treatment of hyperlipidaemia and NAFLD than the dosage of PMR. This coincided with the prescribed dosage listed in the Pharmacopoeia of the People's Republic of China (2010 edition), 3-6 $\mathrm{g}$ for PMR and 6-12 $\mathrm{g}$ for PMRP.

The human intestinal permeability of TSG, EN, RN, AE, RL, PL, and EG was evaluated using the Caco-2 cell monolayer model. In this research the permeabilities of seven compounds were passive diffusion because the drug concentrations in AP side were far above BL side.

Some researchers $[19,20]$ found that the absorption of passive-transport-based compounds has to do with its polarity. The greater the polarity of the compound is, the smaller the $P_{\text {app }}$ value is. Coincidently, just from the point of view of each values, smaller $P_{\text {app }}$ of TSG, EG, and PL in this research also proved this point.

TSG and EN both showed low recovery rates and low $P_{\text {app }}$ in this research. We predict that large partitions of EN and TSG may accumulate or metabolise in the Caco- 2 cells. TSG, EN, or their metabolites may be released from the Caco2 cells and display their corresponding effects subsequently. However, further validation must be carried out to confirm this hypothesis.

The quantitative relationships in researches between physical-chemical properties values and $P_{\text {app }}$ displayed higher 
correlation Gibbs energy, heat of form, and apparent permeability coefficient. The higher the Gibbs energy was, the higher the apparent permeability coefficient was. The same thing applied to the heat of form. This was in accordance with a previous research [21] showing the Gibbs (free) energy contributions to the membrane partitioning of lipidated proteins. Although the mechanism why predicted boiling point, melting point, critical temperature might affect the apparent permeability coefficient, this research provided basic clues for the further research.

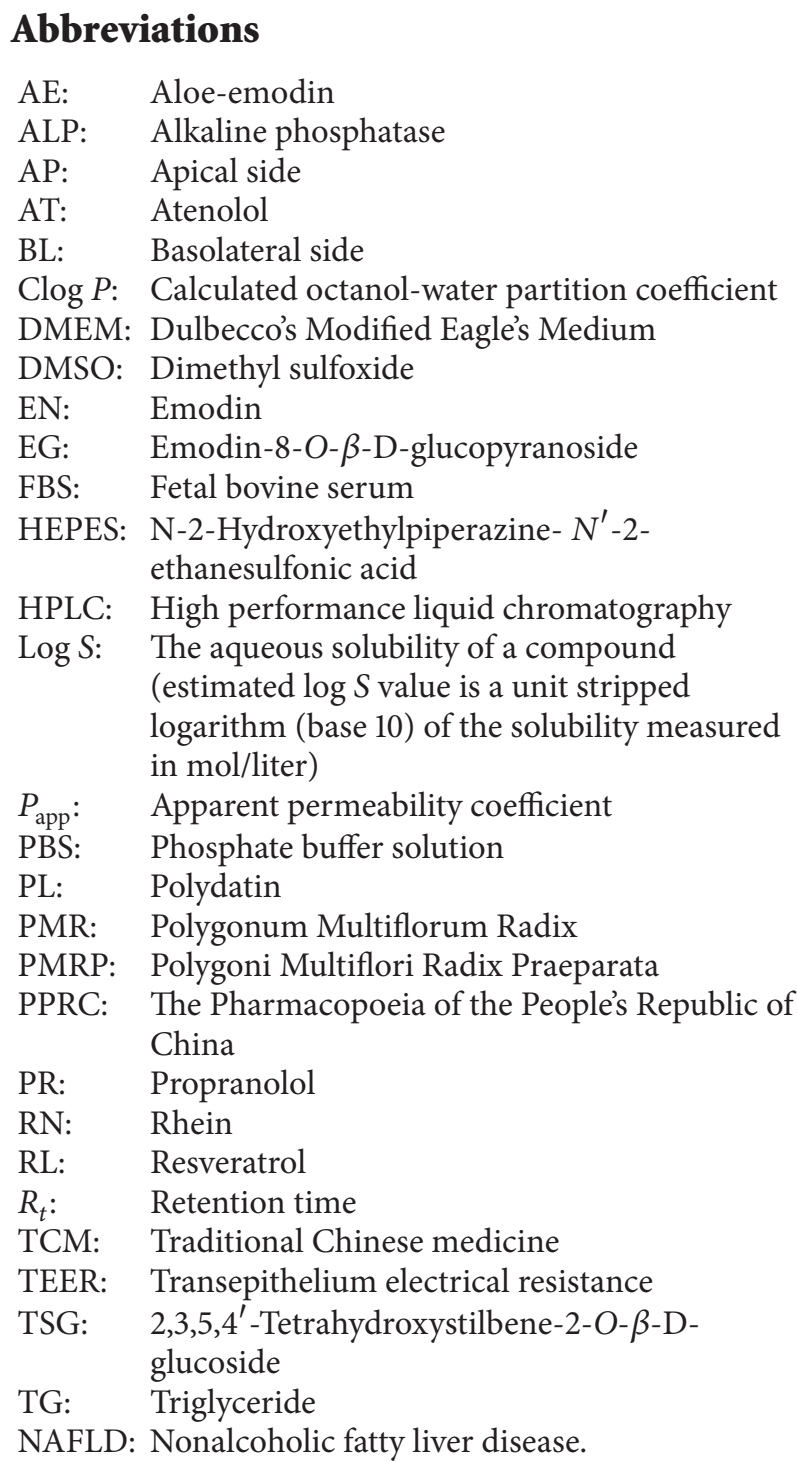

\section{Conflict of Interests}

The authors declare that there is no conflict of interests. They declare that they have no financial and personal relationships with other people or organizations that can inappropriately influence their work. There is no professional or other personal interest of any nature or kind in any product, service, and/or company that could be construed as influencing the position presented in this paper.

\section{Acknowledgments}

This research was financially supported by the National Natural Science Foundation of China (Grant nos. 30760312 and 81060337), Key Public Project of Ministry of Science and Technology and Ministry of Finance, China (201107007), and the Natural Science Foundation of Yunnan Province, China (Grant no. 2010ZC105).

\section{References}

[1] Y. Cao, M. Zhang, H. Z. Yu et al., "Study on determination of resveratrol in different plants and same plant tissues," Hunan Forestry Science \& Technology, vol. 30, pp. 32-34, 2003.

[2] B. Avula, V. C. Joshi, Y.-H. Wang, and I. A. Khan, "Simultaneous identification and quantification of anthraquinones, polydatin, and resveratrol in Polygonum multiflorum, various Polygonum species, and dietary supplements by liquid chromatography and microscopic study of Polygonum species," Journal of AOAC International, vol. 90, no. 6, pp. 1532-1538, 2007.

[3] W. J. Wang, Y. M. Xue, R. H. Zhao et al., "Research Progess on the chemical compositions and pharmacological effects of Radix Polygonum Multiflorum," Journal of Yunnan College of Traditional Chinese Medicine, vol. 30, pp. 60-64, 2007.

[4] T. Yi, K. S. Y. Leung, G.-H. Lu, H. Zhang, and K. Chan, "Identification and determination of the major constituents in traditional Chinese medicinal plant polygonum multiflorum Thunb by HPLC coupled with PAD and ESI/MS," Phytochemical Analysis, vol. 18, no. 3, pp. 181-187, 2007.

[5] Chinese Pharmacopoeia Commission, Pharmacopoeia of the People's Republic of China, Medico-Pharmaceutical Science \& Technology Publishing House, Beijing, China, 2010.

[6] J. Gao, E. D. Hugger, and M. S. Beck-Westermeyer, "Estimating intestinal mucosal permeation of compounds using Caco-2 cell monolayers," Current Protocols in Pharmacology, vol. 7, pp. 1-23, 2000.

[7] V. Milovic, L. Turchanowa, J. Stein, and W. F. Caspary, “Transepithelial transport of putrescine across monolayers of the human intestinal epithelial cell line, Caco-2," World Journal of Gastroenterology, vol. 7, no. 2, pp. 193-197, 2001.

[8] Z. Huang, J. Xing, X. Wang et al., "Intestional absorption and mechanism of tiliani in Caco-2 cell model," China Journal of Chinese Materia Medica, vol. 37, pp. 1315-1318, 2012.

[9] M. Yan, L. Li, H. Li et al., "Effect of $18 \alpha$,-glycyrrhizic acid and $18 \beta$,-glycyrrhizic acid on P-gp function and expression in Caco2 cells," China Journal of Chinese Materia Medica, vol. 37, pp. 99-103, 2012.

[10] X.-Y. Zhang, X. Ke, L. He, and J.-L. Tian, "Transport of limonin in rat intestine in situ and Caco-2 cells in vitro," Yaoxue Xuebao, vol. 47, no. 2, pp. 229-232, 2012.

[11] Y. Wang and X.-W. Yang, "Intestinal transport of free anthraquinones in Caco-2 cell model," Chinese Journal of Natural Medicines, vol. 6, no. 2, pp. 141-145, 2008.

[12] M. Yazdanian, S. L. Glynn, J. L. Wright, and A. Hawi, "Correlating partitioning and Caco-2 cell permeability of structurally diverse small molecular weight compounds," Pharmaceutical Research, vol. 15, no. 9, pp. 1490-1494, 1998.

[13] Y. H. Zhao, J. Le, M. H. Abraham et al., "Evaluation of human intestinal absorption data and subsequent derivation of a quantitative structure-activity relationship (QSAR) with the Abraham descriptors," Journal of Pharmaceutical Sciences, vol. 90, pp. 749-784, 2001. 
[14] C. A. Lipinski, F. Lombardo, B. W. Dominy, and P. J. Feeney, "Experimental and computational approaches to estimate solubility and permeability in drug discovery and development settings," Advanced Drug Delivery Reviews, vol. 46, no. 1-3, pp. 3-26, 2001.

[15] X. Gao, Y.-J. Hu, and L.-C. Fu, "Blood lipid-regulation of stilbene glycoside from Polygonum multiflorum," Zhongguo Zhongyao Zazhi, vol. 32, no. 4, pp. 323-326, 2007.

[16] C. K. Xiang, R. Wang, and Z. F. Yuan, "Study on effect of polygonum multiflorum exract on lipid metabolism and its Anti-Oxidation in SD rats with hyperlipemia," China Pharmaceuticals, vol. 18, pp. 19-20, 2009.

[17] N. Li, Z. Chen, X. Mao, J. Yu, and R. Zhao, "Effects of lipid regulation using raw and processed Polygoni Multiflori Radix in rats fed a high-fat diet," Evidence-Based Complementary and Alternative Medicine, vol. 2012, Article ID 329171, 10 pages, 2012.

[18] M. Wang, R. Zhao, W. Wang, X. Mao, and J. Yu, "Lipid regulation effects of Polygoni Multiflori Radix, its processed products and its major substances on steatosis human liver cell line L02," Journal of Ethnopharmacology, vol. 139, no. 1, pp. 287-293, 2012.

[19] L. Ma, Y. Wang, and X.-W. Yang, "Absorption of dictamnine and skimmianine across human intestinal epithelial in a model of Caco-2 cell monolayers," Chinese Journal of New Drugs, vol. 17, no. 2, pp. 124-128, 2008.

[20] L. Ma and X.-W. Yang, "Absorption of papaverine, la-danosme and cepharanthine across human intestine by using human Caco-2 cells monolayers model," Yaoxue Xuebao, vol. 43, no. 2, pp. 202-207, 2008.

[21] K. Weise, D. Huster, S. Kapoor et al., "Gibbs energy determinants of lipoprotein insertion into lipid membranes: the case study of Ras proteins," Faraday Discussions, vol. 161, pp. 549561, 2013. 


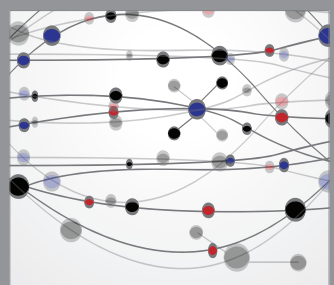

The Scientific World Journal
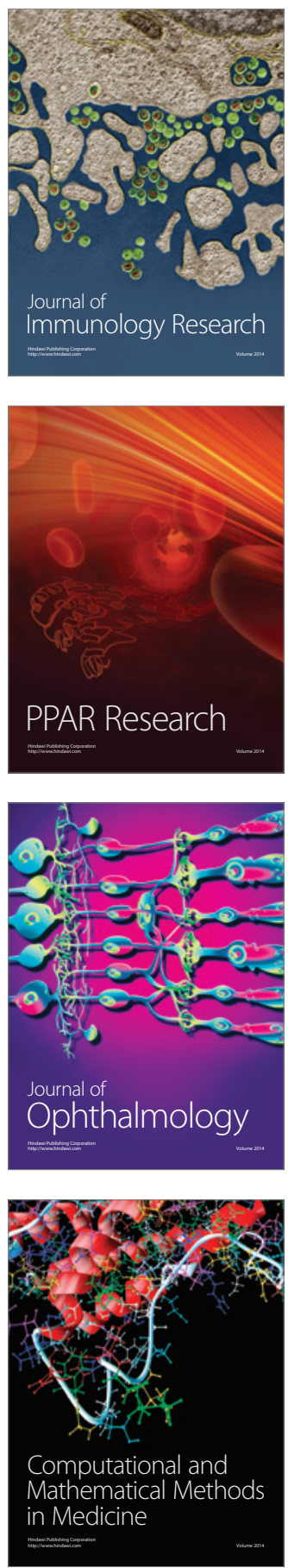

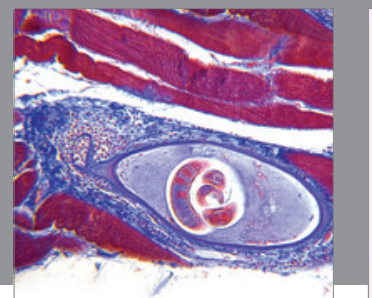

Gastroenterology

Research and Practice
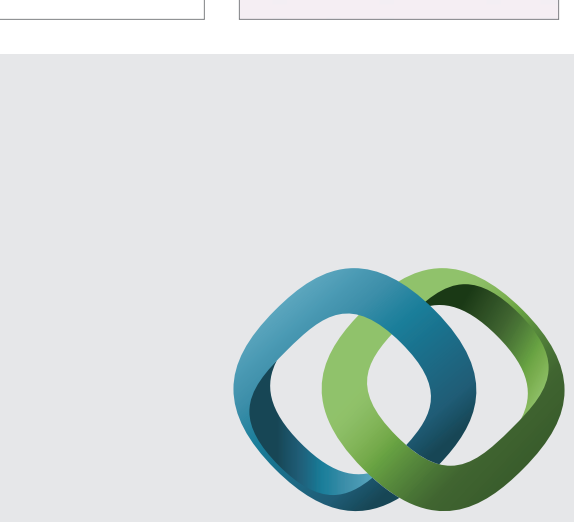

\section{Hindawi}

Submit your manuscripts at

http://www.hindawi.com
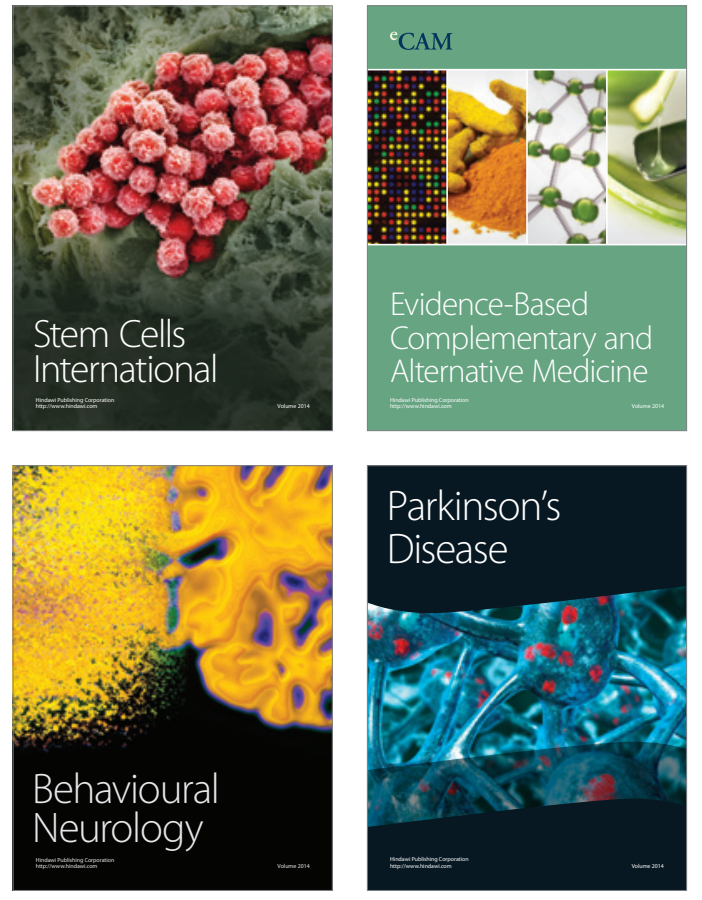
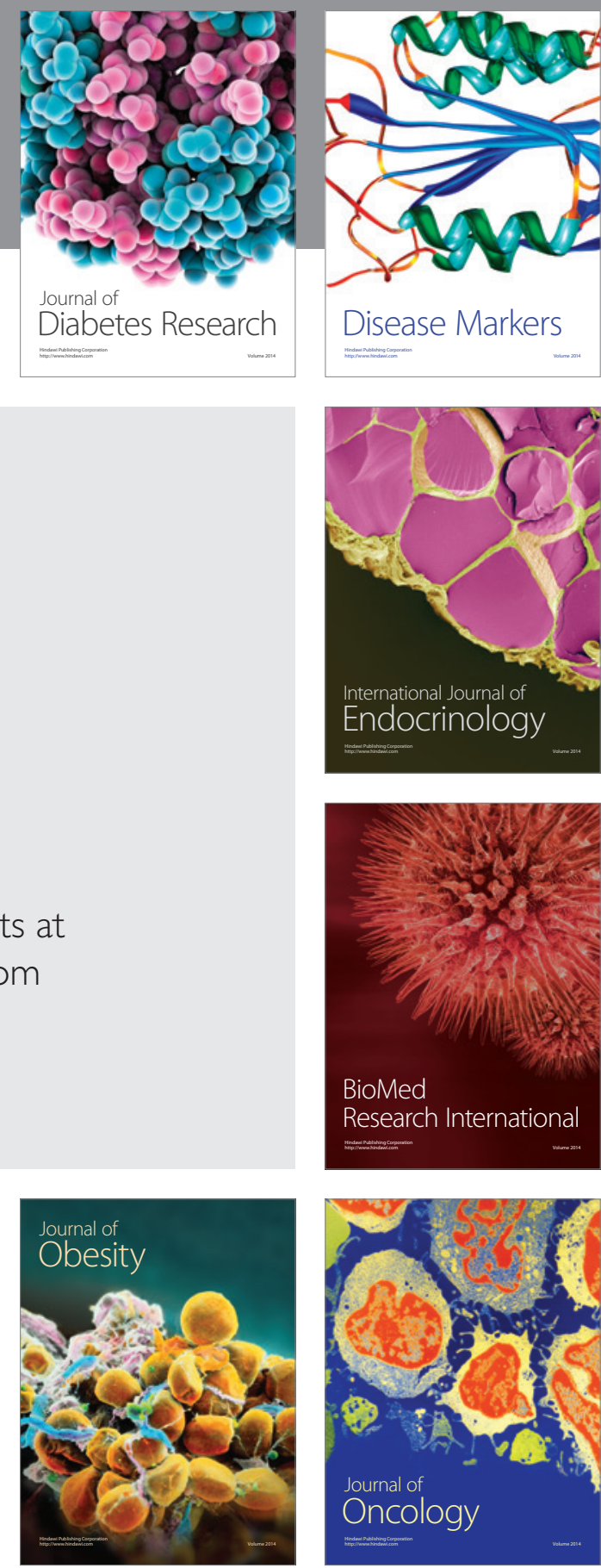

Disease Markers
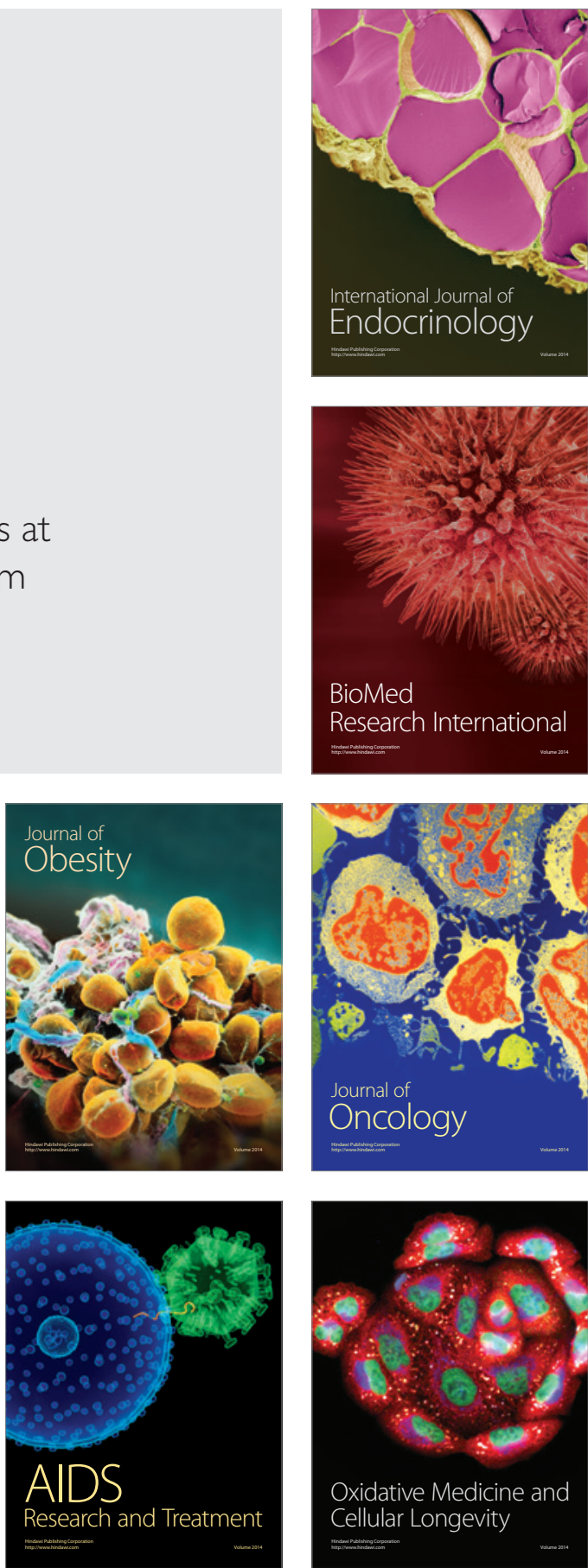